Madrygal. Revista de Estudios Gallegos

ISSN: 1138-9664

\title{
Narrativa
}

\section{Conto para a Balteira}

Henrique Marques Samyn

É por acaso que pasa por aquela rúa. Acostuma facer outro camiño: seguir pola Ronald de Carvalho en dirección á Barata Ribeiro, e alí colle o bus. Hoxe tivo que resolver outros asuntos, e é por iso que baixa a Prado Júnior. Mero acaso.

Recoñece os rostros a distancia. Ao principio, hesita: hai moito tempo que non os ve -dez, quince anos? Cando envellecemos, o tempo pasa máis rápido. No momento en que os ollos se encontran, as dúbidas disípanse. O sorriso é reconfortante, o acaso non parece acaso: xusto hoxe! As débedas, a maldita crise; o aluguer, os fillos; o despido inevitábel. A cabeza fervendo, a noite maldormida.

- Traballo, para que traballo? Senta aí, carallo! Vai tanto tempo...

Precisa diso, realmente: hoxe, agora. Pasou a noite en claro, rolando na cama, andando dun lado para outro. Acordou pensando no peor: dar logo un fin a todo, mais como? Levar aos fillos tamén? Sente percorrendo o corpo aquel mesmo calafrío que lle veu xunto con esa idea -nunca lle pareceu posíbel tan sequera matinar nunha actitude dese tipo; cando vía nos xornais noticias de homes que o fixeran, sempre tiña palabras duras para condenalos. Canallas! Covardes! De repente, convertérase nun deles: pensara en comportarse como un covarde, como un canalla, e todo facía sentido. En que se transformara? Quedar alí talvez o levase a reencontrarse consigo mesmo. Algúns minutos. Algunhas horas.

-Estabamos falando de María... lembras aquel día? A historia da vella? — pregunta Xoán, mentres chama ao camareiro.
Lembrábase, está claro. Onde foi? Na Lapa?

—Non, foi na Gloria! — responde Vasco, abrindo un sorriso. Sempre a sorrir, o vello Vasco, agora sen uns cantos dentes. - Lembro, eu estaba alí! Eu e o García!

-O García, o que morreu? - pregunta Xoán.

-Que dis, el morreu? Cando, como?

-Atropelado — responde Xoán-, en plena Dias da Cruz... non o sabías?

Non, había tempo que non o vía... había tempo que non vía a ninguén. As obrigas, o traballo, foise afastando de todo, perdeu o contacto con todo o mundo. A voz soa melancólica; mais Vasco ri outra vez, retoma a historia, alegra a mesa.

—Estabamos alí eu, ti e o García... aí pasou unha vella, unha mendiga - e Vasco ri mentres o conta; ri só, e porque el ri os outros tamén rin-, pasou unha vella, e ti metícheste con ela, nen lembro o que lle dixestes - sen dentes, o riso do Vasco torna todo máis hilarante-, e María ía pasando, e pensou que fose con ela! Pensou que fose con ela, a María! Púxose brava, baixou os santos do ceo, colleu o vaso de cervexa, tiroullo na cara! - E case caín da cadeira, gargallando, batendo na perna coa man pesada, o rostro vermello. - Eu lémbrome, eu lémbrome...

El xa escoitara o Vasco contar esa historia decenas, talvez centenas de veces; até o punto de que era como se el tamén estivese alí, naquela situación tantas veces repetida. Aínda así, el ri; e talvez Xoán tamén ría porque Vasco ri. Cando as risadas se misturan, el lembra 
as outras veces que estivo cos dous amigos -e cando Vasco dixo esas mesmas palabras, gargallando dese mesmo xeito. É como se, subitamente, aquel tempo que os separaba dos amigos desaparecese: non os vía desde hai dez, quince anos, mais nada se transformou en todo ese tempo. Alí están os tres, só falta o Pedro; xuntos, rindo e bebendo cervexa. Porque ri, esquece a dor. As risadas do Vasco disípanse aos poucos; o rostro fica menos vermello, mais mantén o sorriso -un breve intervalo entre gargalladas, que resurxirán polo menor motivo. Xoán ben o sabe: non perderá a oportunidade.

—Este daquí é pobre por causa dela — di, rindo, sinalando ao Vasco-, é pobre por causa dela! Cantas veces te pasou para atrás? - E o outro, como era de esperar, abre novamente as gargalladas. - Pedía vinte reais, cincuenta, comezaba unha conversa... e deixaba a ese parvo esperando - fala nun ton malicioso, mollando as palabras con grolos de cervexa. - Perdiches moito pola súa culpa... - Se perdín! —admite o Vasco, outra vez vermello, outra vez gargallando.

El mira o reloxo, contrariado: non quere saír, aínda que deba. Colle o vaso de cervexa, bebe o último grolo; fita a espuma cun ollar melancólico, esboza un xesto para levantarse. -Oh, oh, a onde vas? - Xoán levántase, agárrao polo brazo; precisa ir, di, resolver os problemas. - Non agora, di Xoán, chamando ao camareiro, erguendo a copa vacía. Non precisa dicir nada máis: el quere ficar. Para que ter présa? Non ten diñeiro, cheo de débedas... Decide quedar: ten o resto da semana, ten o resto da vida para lidar cos problemas; agora, ten polo menos un momento de alegría. - E mira quen está chegando! —di o Xoán, apuntando para o outro lado da calzada. - Ese de aí fixose rico e desapareceu! - grita o Pedro do medio da rúa. Ese é o mesmo Pedro, pensa? Case irrecoñecíbel: xa case sen cabelos, o corpo pesado, a barba cubrindo o rostro.

- Ese de aí sabeo todo sobre ela - berra o Vasco, enchendo outra copa de cervexa-, até foi enfeitizado por ela! - Pola Balteira? - indaga Pedro, encendendo un cigarro. - Rapaz, aquilo acabou comigo... - Pedro ri, Vasco ri. - Eu díxenlles que non se metesen, que ela sabía desas cousas... e ti con quen te fuches meter? - Xoán fala cun ollar cínico. - E ti non, Xoán? Ti non? - Xoán ergue os ombros, como quen nada ten que ver con iso. - Está claro, ti estabas sempre alí, fregués fiel, sempre cun diñeiriño para a Balteira - di Vasco, fitando o Pedro cunha expresión cómplice. Xoán olla para baixo, un sorriso no canto da boca... cómplices alí son os catro.

$\mathrm{Na}$ mesa, as garrafas baleiras reflicten a luz do día que acaba. As lembranzas enbarállanse, as palabras atropélanse. Rin, gargallan. Son catro vellos, pensa; a iso vense reducidos: catro vellos, nunha taberna de Copacabana, a quen pouco resta alén de buscar a alegría nas lembranzas. El a punto de perder o emprego, cheo de fillos e débedas; o Vasco bebendo de máis, os ollos xa turbios, a voz cansada; o Xoán aínda con problemas de saúde, os remedios no peto da camisa gastada; o Pedro calado, algo tristeiro, fitando o vacío cun ollar melancólico. Catro vellos, buscando un no outro, e nas memórias compartidas, un breve momento de felicidade.

Subitamente, o indesexábel silencio. É preciso enchelo dalgún modo; é preciso esconder ese vacío insoportábel.

—E por onde anda María? — pregunta.

Os tres ollan para el, o espanto estampado nos rostros.

—Ti non o sabes? —pregunta Xoán, perplexo, desviando o ollar para o Vasco.

- A Balteira morreu - responde Pedro, de cabeza baixa - a Balteira morreu.

Non, el non o sabía.

Xoán colle o móbil, desliza o dedo sobre a pantalla partida.

- Atoparon onte o corpo - di Pedro, coa voz opaca-, na Lapa. Tres tiros.

Xoán exhibe unha foto no móbil.

O corpo aínda exhibe a beleza doutrora. Si, está envellecido, mais é aínda o corpo da Balteira -e aínda exhibe as curvas por tantos desexadas. Manchas de sangue tinguen o vestido branco, aberto á altura do peito, deixando os seos parcialmente expostos. Espallados ao redor da cabeza, os cabelos negros parecen fundirse co escuro asfalto. Dun lado do corpo, un bolso dourado, entreaberto; do outro lado, un zapato vermello.

—Sería un asalto? — pregunta. Ninguén responde. Talvez teñan tentado roubarlle o bolso, pensa; mais entón decátase do vestido aberto, a curva dos seios... houbo loita, seguro; talvez ela teña gritado, até que os tiros de repente a calaron. - Tres tiros — di Pedro. Unha rasgadura no vestido, perto do ombro dereito. 
Séntese invadido por un estraño pudor, ao ver o colo exposto, mollado por un sangue aínda fresco - de onde esa vergoña, agora, se nunca a sentiu cando estaba viva, en tódalas veces que gozou daquel corpo? Quere desviar os ollos, mais Xoán permanece inmóbil: tamén el observa o teléfono que ten na man, un pouco trémula. Quere romper o silencio, mais non sabe como. Ninguén respondeu a pregunta. Ninguén enche as copas vacías. Ninguén os interrompe, nen o camareiro. Un silencio que pesa como o chumbo.

-Dicían que estaba tola - murmura Xoán, talvez igualmente incomodado. - E estábao? —Non sei — responde - , sempre me pareceu medio tola, a Balteira. E aos tres, sen que fose necesario dicir unha palabra, ocorríanselles as mesmas lembranzas: as incontábeis veces en que a Balteira varaba as madrugadas, danzando e cantando, ás veces sacando a roupa para exhibir o corpo que a tantos causara tanto deleite. Inesquecíbel aquel día en que, de repente, surxiu no medio da Cinelandia, entoando a súa canción preferida $-\mathrm{O}$ que Balteira ora quer vingar, das desonras que no mundo prendeu...-, e comezou a bailar soa, rodando a saia, os ollos fechados, coma unha posesa; e outros aos poucos foron chegando, bébedos e vagabundos, putas e mendigas, e de repente todo se tornara unha inmensa festa, unha colosal celebración; e no medio de todo María Balteira, encantando ao seu desvariado séquito de marxinais.

- Non estaba tola — di Pedro. - Talvez murmura Xoán. Mais que sabedes? Non sabedes nada, porque hai anos que non lle dirixiades a palabra. Cando eran máis novos, buscaran o seu corpo, del beberan, saciaran desexos; despois a súa compaña tornouse dispensábel, e cada vez máis indesexábel, ata que pasaron a ignorala, dedicándolle o mesmo desprezo dispensado a calquera desas vellas mulleres invisíbeis aos ollares masculinos.

—Non o entendedes? — pregunta Vasco, a voz mollada de alcohol e bágoas. -Nós matamos a Balteira. - Ninguén aquí deu ningún tiro - di Xoán. - Non importa, —insiste Vasco -nós matamos a Balteira, todos nós.

Xoán balancea a cabeza, os outros non din nada. Vasco chora.

$\mathrm{Na}$ mesa, copas e garrafas baleiras esperan por un camareiro que non chega. 